Research papers

\title{
Forecasting near-surface weather conditions and precipitation in Alaska's Prince William Sound with the PWS-WRF modeling system
}

\author{
Peter Q. Olsson ${ }^{\mathrm{a}, \mathrm{b}, *}$, Karl P. Volz ${ }^{\mathrm{a}, \mathrm{b}}$, Haibo Liu ${ }^{\mathrm{c}}$ \\ ${ }^{a}$ Alaska Experimental Forecast Facility, University of Alaska Anchorage, 2811 Merrill Field Drive, Anchorage, AK 99501, USA \\ ${ }^{\mathrm{b}}$ Alaska State Climate Center, Environment and Natural Resources Institute, University of Alaska Anchorage, 2811 Merrill Field Drive, Anchorage, AK 99501, USA \\ ${ }^{\mathrm{c}}$ Lamont-Doherty Earth Observatory, Columbia University, 1 Route 9W-P.O. Box 1000 Palisades, NY 10964-8000, USA
}

\section{A R T I C L E I N F O}

\section{Article history:}

Received 16 February 2011

Received in revised form

12 December 2011

Accepted 29 December 2011

Available online 7 February 2012

Keywords:

Weather research and forecasting model

(WRF)

Prince William Sound

North Gulf of Alaska

Quantitative precipitation forecasting

Model verification

Surface winds

\begin{abstract}
A B S T R A C T
In the summer of 2009, several scientific teams engaged in a field program in Prince William Sound (PWS), Alaska to test an end-to-end atmosphere/ocean prediction system specially designed for this region. The "Sound Predictions Field Experiment" (FE) was a test of the PWS-Observing System (PWS-OS) and the culmination of a five-year program to develop an observational and prediction system for the Sound. This manuscript reports on results of an 18-day high-resolution atmospheric forecasting field project using the Weather Research and Forecasting (WRF) model.

Special attention was paid to surface meteorological properties and precipitation. Upon reviewing the results of the real-time forecasts, modifications were incorporated in the PWS-WRF modeling system in an effort to improve objective forecast skill. Changes were both geometric (model grid structure) and physical (different physics parameterizations).

The weather during the summer-time FE was typical of the PWS in that it was characterized by a number of minor disturbances rotating around an anchored low, but with no major storms in the Gulf of Alaska. The basic PWS-WRF modeling system as implemented operationally for the FE performed well, especially considering the extremely complex terrain comprising the greater PWS region.

Modifications to the initial PWS-WRF modeling system showed improvement in predicting surface variables, especially where the ambient flow interacted strongly with the terrain. Prediction of precipitation on an accumulated basis was more accurate than prediction on a day-to-day basis. The 18-day period was too short to provide reliable assessment and intercomparison of the quantitative precipitation forecasting (QPF) skill of the PWS-WRF model variants.
\end{abstract}

(c) 2012 Elsevier Ltd. All rights reserved.

\section{Introduction}

Alaska's Prince William Sound (PWS) is a significant embayment on the coast of the Northern Gulf of Alaska (NGOA), (Schoch and McCammon, in press). As such, it is subject year-round to the many active weather systems experienced by the NGOA. Climatologies of weather of the NGOA, on time scales of days to decades, can be found in Wilson and Overland (1986) and Stabeno et al. (2004), among others, while Mesquita et al. (2010) discuss seasonal storm tracks for the greater North Pacific and Bering Sea region. This general region is commonly found to have regions of strong baroclinicity, and hence frequent extratropical cyclone activity, with the NGOA tending to be a very common region of cyclolysis, especially in fall and summer.

\footnotetext{
* Corresponding author at: Alaska Experimental Forecast Facility, University of Alaska Anchorage, 2811 Merrill Field Drive, Anchorage, AK 99501, USA.

Tel.: + 19077867234 .

E-mail address: olsson@aeff.uaa.alaska.edu (P.Q. Olsson).
}

The warm season, being the annual minimum in baroclinicity in the NGOA, tends to be the least stormy time of the year there. Although generally less stormy in the summer than during the winter months, it does occasionally see transient surface lows, creating periods of higher winds and precipitation, bracketed by periods of calmer weather associated with surface high pressure in the Gulf of Alaska.

Meteorological conditions within PWS are characteristically different than those in the off-shore waters of the NGOA. In several locations, deeply-incised glacial valleys-often in the form of fjords-penetrate the bounding coastal range of the PWS. The wind direction in these mountain gaps is largely determined by the local topography, with winds flowing up or down the valley axis depending on the overlying pressure field. In contrast, winds unconstrained by topography tend to approach so-called geostrophic balance, with flow perpendicular to the pressure gradient, and low pressure to the left of the flow in the northern hemisphere. In PWS, both of these wind regimes can coexist, often resulting in localized winds in and near gaps that are almost 
perpendicular to the unconstrained flow. Accurate simulation of these local gap wind features with a numerical model requires an adequate depiction of the underlying topography. In regions such as the PWS, this necessitates a model with a horizontal grid spacing on the order of a few kilometers. and a very well-resolved digital elevation model (DEM) to determine grid-cell height.

This paper reports on efforts to predict surface winds and quantitative precipitation in the PWS during a field experiment. Forecast results were compared to observations to assess model fidelity. To address identified deficiencies, two different model variants were introduced, using differing model geometries and varying parameterizations of physical processes. These model variants were then implemented to produce retrospective simulations for the same field experiment period. Finally, the various model variant simulations and observations were inter-compared to assess the relative predictive skill. During this process, several important issues for numerical forecasting in the PWS were identified.

\subsection{Sound Predictions field experiment}

During the period of July 17, 2009-August 3, 2009, several scientific teams engaged in a field program in PWS to test an end-to-end atmosphere/ocean prediction system. This multimodel prediction system (atmosphere, ocean and waves) was designed over a five-year period as a component of the encompassing PWS Observing System (PWS-OS). The model development and deployment were sponsored by the Alaska Ocean Observing System (AOOS) and the Oil Spill Recovery Institute (OSRI). This culminating experiment, known as the "Sound Predictions Field Experiment" (here after referred to as the FE) (Schoch and McCammon, in press) was designed to test the predictive capabilities of the ocean, wave, and atmospheric components of the modeling system and gain insight on how the models could be enhanced. This manuscript details the procedures and results of this effort for the atmospheric modeling component and also results of related follow-on studies.

\subsubsection{Synoptic environment during the FE.}

During much of the FE, the west coast of North America was under the influence of a well-established surface high pressure ridge, while the Bering Sea and west coast of mainland Alaska were beneath a long wave trough (Fig. 1). Other studies of the North Pacific long wave patterns (e.g., Stabeno et al., 2004) found that pressure patterns in the NGOA during the warm season tended to be rather transient, albeit with some interannual variation, so it is difficult to say whether the stable pattern observed throughout most of the FE was unusual or not.

A broad region of low surface pressure in the southern Bering Sea, associated with the Bering upper trough, was observed in the Gulf from 17 July through the end of the month. Within this region, a series of surface low pressure centers moved in generally cyclonic paths beneath the center of the upper low that had become established above the Bering Sea region (Fig. 2).

By contrast, southeast Alaska and the west coast of Canada came under the influence of a ridge of high pressure at all levels that was established late on 19 July over western Canada and continued through the end of the FE. At the surface, the high pressure ridge stretched northwestward along the Pacific coast terminating in the area of the north Gulf coast very near to Cook Inlet and PWS.

Short waves moving through the upper trough situated over the Bering created a series of lows and frontal systems giving rise to intermittent periods of stronger surface winds and precipitation in the offshore areas of the NGOA from 19 July through 29 July.

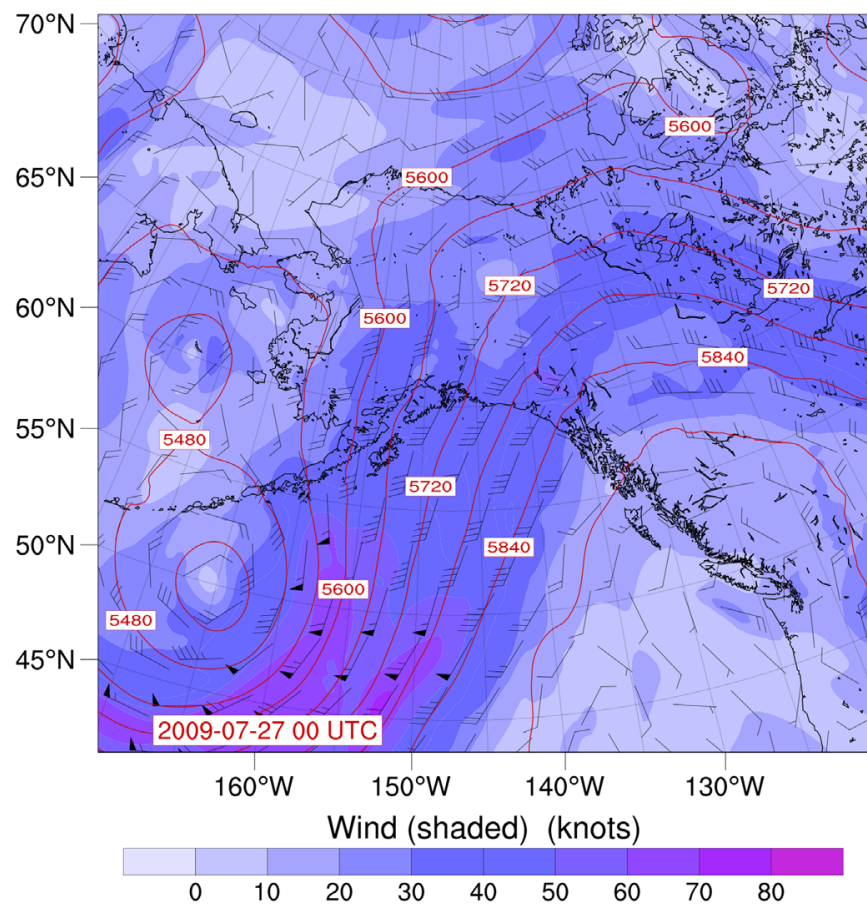

Fig. 1. NAM 00 UTC initialization for 27 July, 2009, $500 \mathrm{hPa}$ level. Mid-level evidence of the anchor low is clearly visible south of the central Aleutian Chain.

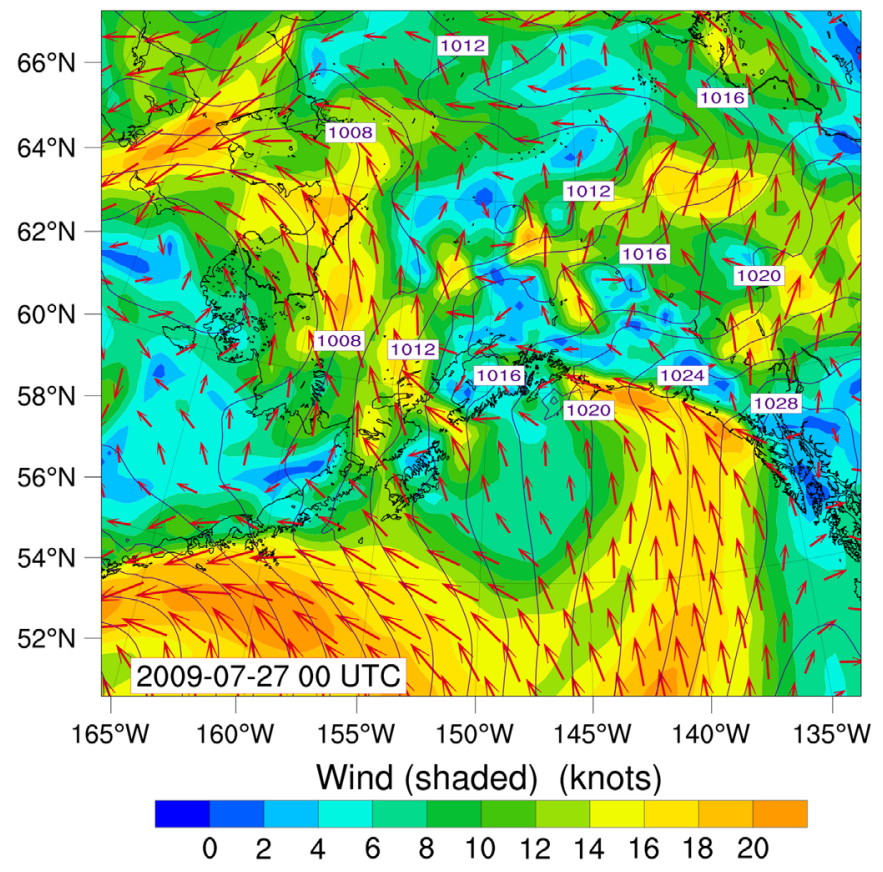

Fig. 2. NAM 00 UTC initialization, surface chart. Significant features include surface low in the Bering Sea and a strong E-W pressure gradient over the Chugach Mountains north of PWS.

The east-west pressure gradient that was created between the ridge stretching northward from Yakutat, AK and the large surface low in the western Bering Sea was the dominant surface feature for PWS during the FE.

Within PWS, the presence of the upper trough and the series of short waves contributed to a lengthy period of unsettled weather beginning late on 20 July and continuing until 1 August. The high terrain to the north of the PWS and the existence of high pressure along the coast of SE Alaska along with approaching surface 


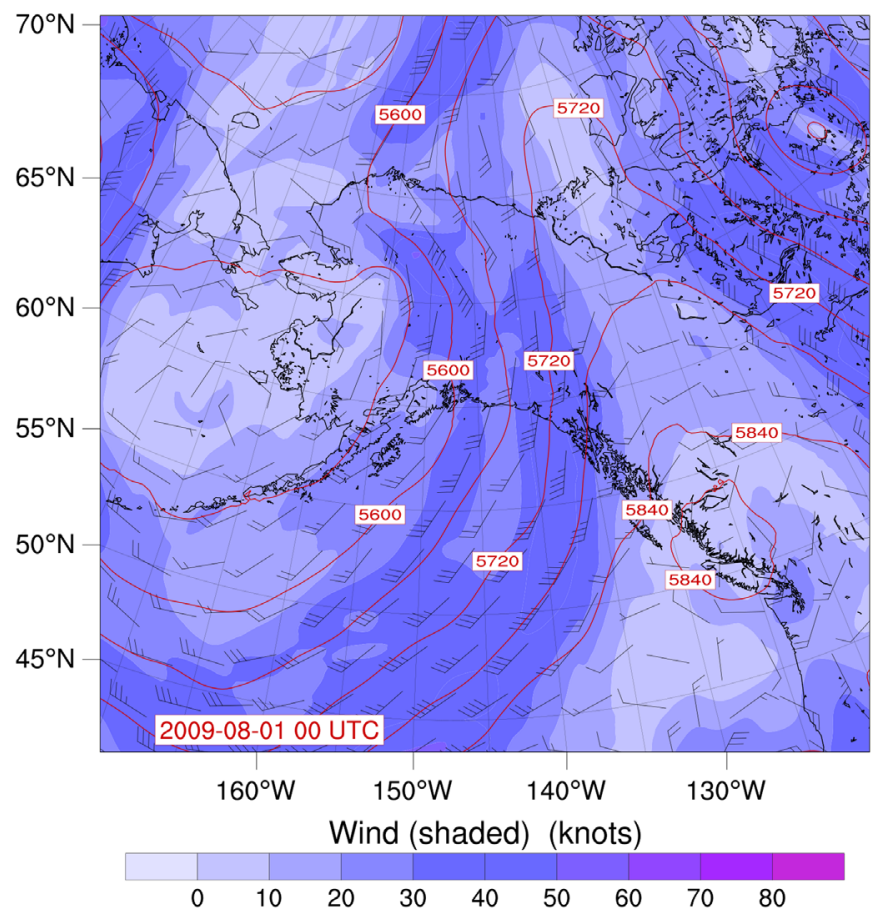

Fig. 3. NAM 00 UTC initialization for 1 August, 500 hPa surface. Note the strong mid-level jet along the Alaska-Canada border.

troughs periodically created very strong pressure gradients across the Chugach Mountains, the range that borders PWS to the north. (Fig. 2).

The wind directions in the non-sheltered regions of PWS were consistently southerly during the FE, with a slight east or west component that varied over time. Both wind speed and direction resulted from the east-west pressure gradient that formed on July 20 , and was reinforced periodically through 29 July by the approaching upper troughs and associated surface features.

Although the anchor low centered over the Bering Sea continued to influence the PWS region as several fronts moved through Cook Inlet and PWS after 29 July, the surface pressure gradients became less pronounced as the upper flow became more westerly beginning about 1 August (Fig. 3). By 00Z 1 August, the 500-hPa jet axis had moved to the east of the region and an area of surface high pressure was building in the NGOA (Fig. 4). Surface winds remained steady out of the west and north for the remainder of the period as the local pressure gradient became oriented south to north in PWS.

\subsubsection{Surface winds during the $F E$}

In light of the above discussion, it is useful to consider a time series of surface winds in PWS, which is perhaps best represented (in as much as any single point can be representative of the wind field in such complex terrain as that of PWS) by the National Data Buoy Center (NDBC) buoy 46060 (West Orca Bay) in east-central PWS. (Fig. 5; see locations of the various surface observing sites in Table 2 and Fig. 7).

Most remarkable in Fig. 5 is the nearly constant ESE wind direction for the period 21 July through 29 July-an episode including several mid-level short wave passages-while the wind speed shows considerable variability on a number of time scales. This suggests the terrain has considerable control over wind direction under a variety of generally $\mathrm{E}-\mathrm{W}$ pressure gradient

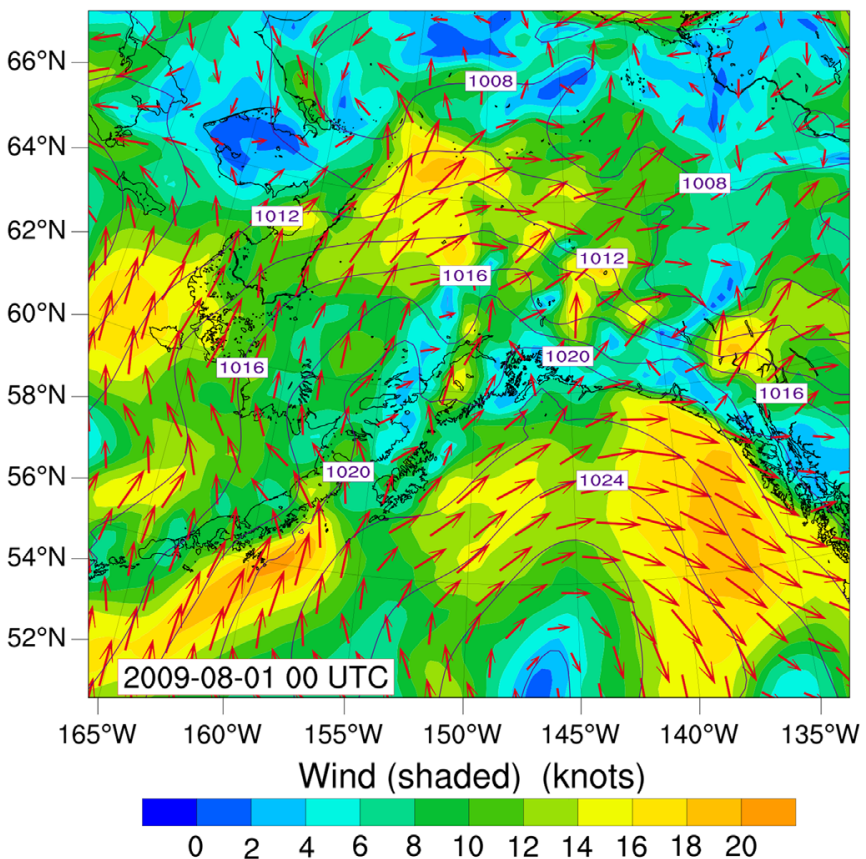

Fig. 4. NAM 00 UTC initialization for 1 August, 2009, surface chart. At this point towards the end of the $\mathrm{FE}$, the pressure gradient relaxes and becomes more $\mathrm{N}-\mathrm{S}$ than E-W as a surface high-pressure ridge builds into the NGOA.

configurations. The maximum observed wind speed during the FE at $46060,16 \mathrm{~m} \mathrm{~s}^{-1}$ (31 kt), occurred on 06 UTC 22 June.

\section{Methods}

The purpose of this paper is to present and evaluate the atmospheric forecasts/simulations produced as part of the FE-in particular the surface $(10-\mathrm{m})$ wind fields. This is done through a statistical comparison of the single-point wind forecasts with three surface buoys within PWS. The forecast wind statistics are then used as the basis for a comparative retrospective sensitivity study using model variants with finer spatial (and concomitant temporal) resolution and more complex physical parameterizations. The intent of this process is to evaluate both the current state of forecasting skill and to provide guidance on how this might be improved and at what cost of computational resources.

The modeling portion of the FE was largely focused on integration of data from different models. From the atmospheric modeling perspective this required accurate $(u, v)$ fields near the surface for implementation as forcing functions in the ocean and wave models. A secondary consideration was the ability of the model to produce a reasonable quantitative precipitation forecast (QPF) that, coupled with a surface hydrological model, might lead to better warm-season runoff predictions for PWS (e.g., Colas et al., preparartion).

\subsection{PWS-WRF}

The atmospheric modeling software developed at the AEFF for use as a component of the PWS-OS modeling system is based on the Advanced Research Weather Research and Forecasting (WRF) model (Skamarock et al., 2008). Several versions of WRF are available; both V 2.2 and V 3.1 were run during FE, while V 3.1 was used in the retrospective simulations. Here, the term 

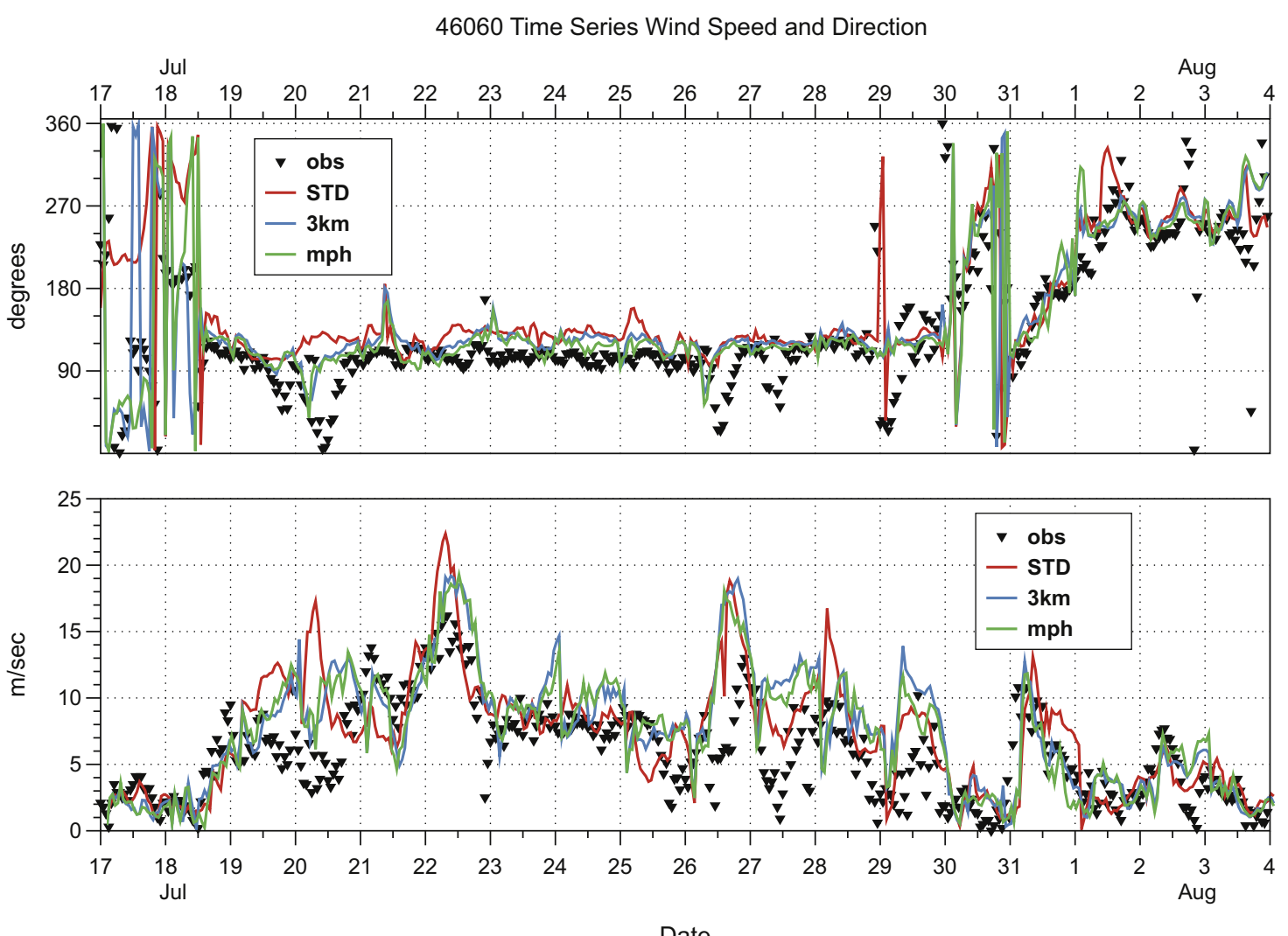

Date

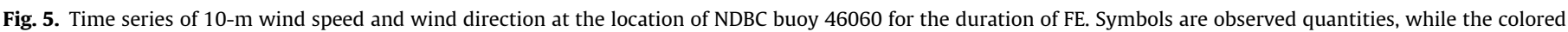

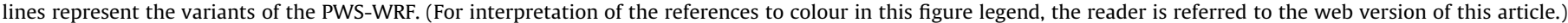

PWS-WRF is used to refer collectively to the modeling system package that includes WRF, the software for initial and boundary condition data processing, and any necessary post-processing of the model output data. Initial and boundary conditions for PWS-WRF are obtained from the operational runs of the National Centers for Environmental Prediction (NCEP) North American Model (NAM). The NAM—since 2006 itself a WRF variant implementing the Nonhydrostatic Mesoscale Model (NMM) physics core-is run four times daily on a $12-\mathrm{km} \Delta x, y$ grid domain spanning North America. At the time of the FE, the highestresolution gridded NAM data operationally available for our Alaskan implementation was on the AWIPS 216 Grid which was resampled from the native NAM grid to $45-\mathrm{km} \Delta x, y$. The forecast data grids necessary to run the PWS-WRF were typically available about $3 \mathrm{~h}$ after the initial integration time. Thus, the PWS-WRF was able to complete 48 -h forecasts within about $5 \mathrm{~h}$ of the initial integration time.

During the FE, the AEFF produced two 48-h forecasts daily (00 and 12 UTC initialization time) with WRF v2.2 and one (12 UTC) using WRF v3.0. The use of PWS-WRF forecast output as forcing for the other real-time models participating in the FE was limited to the 00 UTC v2.2 runs. Both the 00 and 12 UTC forecasts provided guidance for the daily operational field component of the FE.

\subsubsection{STD configuration}

The default configuration for PWS-WRF as used for the FE was identical to that used for routine forecasts that are run twice daily at the AEFF. This configuration, referred to herein as STD (for

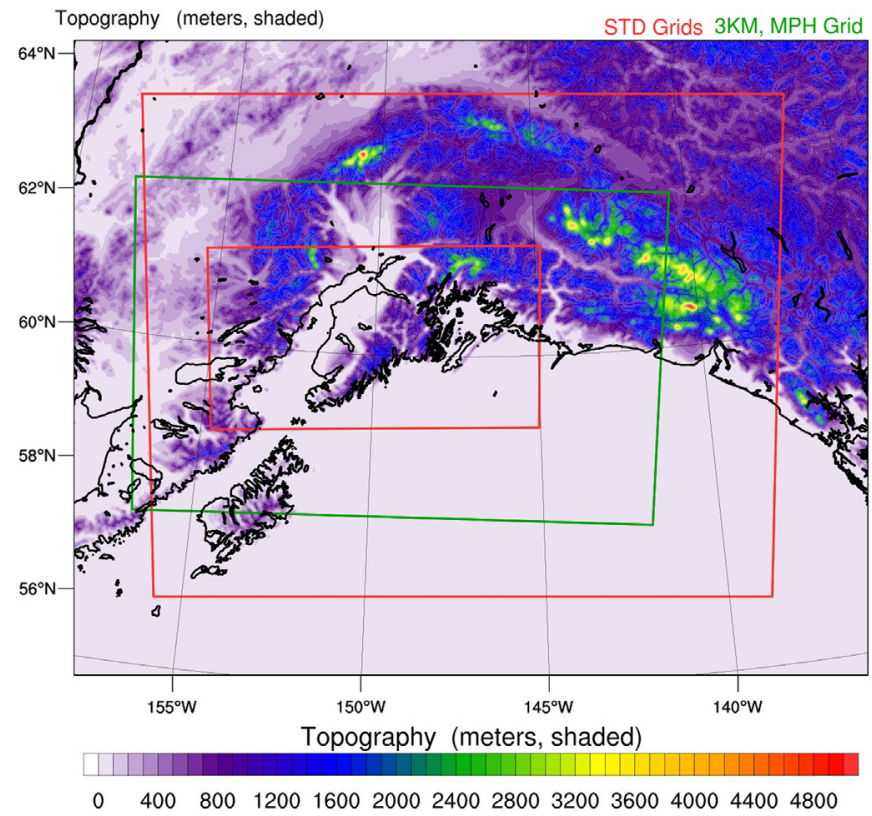

Fig. 6. Locations of the various grid domains for the model runs overlaid on the $30 \mathrm{~s}$. WRF topography set. The 2-grid STD domains are demarcated by the red rectangles. The domain for the $3 \mathrm{KM}$ and MPH runs is given in green. The skewed nature of the green rectangle relative to the STD grids reflects the different map pole-projection point used for the single 3-km $\Delta \mathrm{x}$ grid. Mt. McKinley (elevation$6194 \mathrm{~m}$ ), the highest topography in the model domains, has an elevation of $5931 \mathrm{~m}$ on the STD 12-km $\Delta x$ Grid 1. (For interpretation of the references to colour in this figure legend, the reader is referred to the web version of this article.) 
standard), is a two-way, nested-grid design, implementing a polar-stereographic map projection. The outer domain (Grid 1, $12-\mathrm{km} \Delta x, y$ ) is $90 \times 72$ points, centered on the NGOA coast (outer green box in Fig. 6). The nested inner domain (Grid 2), $141 \times 78$ points with a $4-\mathrm{km} \Delta x, y$, encompasses the Cook Inlet and PWS (inner green box). This implementation was designed such that Grid 1 would capture the larger scales of the sub-synoptic forcing, while Grid 2, with its higher-resolution topography, would resolve the circulations strongly influenced by the complex terrain of the region.

STD was optimized for implementation as the core of the automated forecast system and as such was required to perform reliably in all seasons over the tremendous topographic variations (sea level $\rightarrow 5931 \mathrm{~m}$ ) found on Grid 1 . This put a significant constraint on the spacing of the lowest few levels. The STD configuration had 43 vertical eta levels, with geometric height equivalents for a sea-level point of about $0,54,131,232$, and $358 \mathrm{~m}$, respectively for the lowest five levels.

The physical parameterizations for STD were chosen for reliability in WRF v. 2.2 and retained for consistency's sake in the migration to WRF 3.1. Significant STD parameterization options and values chosen were:

- microphysics: WRF Single-Moment 3-class scheme (WSM3), $m p \_p h y s i c s=3$, (Hong et al., 2004),

- surface layer physics: MM5 similarity theory, sf_sfclay physics $=1$, (Skamarock et al., 2008),

- planetary boundary layer: Yonsei University scheme. bl_pbl_ physics $=1$, (Hong et al., 2006),

- time integration scheme: Runge-Kutte 2nd order, $r k \_o r d=2$, (e.g., Skamarock and Klemp, 1992),

- vertical velocity damping: $w_{-}$damping $=0$ (off),

- time between radiation calls: $30 \mathrm{~min}$,

- upper-level damping: damp_opt=0.

\subsection{Model variant simulations}

Evaluation of the results from the STD simulations and observations suggests that modifying certain aspects of PWSWRF modeling system might increase forecast fidelity, with STD as a benchmark to compare against. Results suggested that certain physical packages could be used and that a different model geometry might be more optimal. This led to a two-step approach: increase in model resolution with the current physics and then enhancement of certain physical parameterizations. In a highly complex, nonlinear system such as WRF-or indeed the atmosphere itself-, it can be very difficult to ascribe causality. Still, this method allows for a degree of attribution as to which modifications produced certain simulation improvements.

\subsubsection{Model geometry-3KM}

There is significant debate as to whether increasing horizontal model resolution actually quantitatively improves numerical forecasts (Brooks and Doswell, 1993; Mass et al., 2002). Studies of interaction of atmospheric circulations with complex terrain (e.g., Doyle, 1997; Davis et al., 1999; Colle and Mass, 2000a) found that greater horizontal resolution enhanced model performance. Other studies found significant improvement in increasing vertical resolution as well (McQueen et al., 1995; Colle and Mass, 2000b).

Our approach was to modestly increase horizontal resolution from 4 to $3 \mathrm{~km}$, producing a more detailed terrain depiction, and also significantly increasing the number of near-surface levels. The former was desirable in the very steep topography of PWS and the latter permitted a better depiction of the near-surface processes that were the object of our modeling exercise.
It was also determined that a single, larger grid would be used for these tests. What we refer to as the $3-\mathrm{km}$ grid domain is the green rectangle in Fig. 6. The domain size was 299 points E-W and 189 points $\mathrm{N}-\mathrm{S}$. This configuration had 48 vertical eta levels, with geometric height equivalents for a sea-level point of 32.4, $64.9,97.8,130.7,163.9 \mathrm{~m}$ for the lowest 5 levels. This geometry along with the physical parameterizations detailed in Section 2.1.1 for STD will be referred to here as the $3 \mathrm{KM}$ variant.

\subsubsection{Physical parameterizations-MPH}

A variety of options are available for the physical processes parameterized in WRF. Furthermore these parameterizations do not operate in isolation from one another. Indeed, some interactions (e.g. between microphysics and radiation), are expected (Olsson et al., 1998) while others (e.g. advection schemes and boundary-layer parameterizations) are more subtle and often unanticipated (Olsson and Harrington, 2000). It is sometimes possible to optimize the parameterization combinations to a particular end, such as convective rainfall (Jankov et al., 2005) or tropical/midlatitude surface variables (Ruiz et al., 2010). For the high-latitude marine environment and topography of PWS-WRF, there is no obvious road map to optimize parameterizations. After consideration of the options we chose the following:

- Microphysics: WRF Double-Moment 6-class scheme, mp_physics= 16, (Hong and Lim, 2006),

- surface layer physics: Eta similarity theory, sf_sfclay_physics =2, (Janjic, 1996, 2002),

- planetary boundary layer: Noah Land Surface Model (NOAH), bl_pbl_physics=2, (Skamarock et al., 2008),

- turbulent kinetic energy advection: positive-definite advection, $t k e \_a d v \_o p t=1$, (Knievel et al.,2007),

- time integration scheme: Runge-Kutte 3nd order, rk_ord=3, (Wicker and Skamarock, 2002; Klemp et al., 2007),

- vertical velocity damping: $w_{-}$damping=1 (yes),

- time between radiation calls: $2.5 \mathrm{~min}$,

- upper-level damping: Rayleigh damping ${ }^{1}$, damp_opt=3, (Klemp et al., 2007).

These all differ from the STD configuration. This choice of options, along with the model geometry of 3KM, are referred to here as the MPH variant.

\subsubsection{Relative computing costs of the variants}

It comes as no surprise that the integrations of the more highly-resolved 3KM and MPH variants required more computing resources than the STD simulations. Table 1 shows the relevant statistics normalized to the appropriate STD values ${ }^{2}$. Beyond the need to integrate at many more points with the 3-km $\Delta x, y$ variants, the smaller grid spacing required a concomitantly smaller time step to maintain model stability. These factors taken together led to significant computational costs. The computing costs associated with the more complex physical parameterizations in MPH vs. 3KM are also apparent. Also, though these two variants share the same physical grid, the MPH output files were about $12 \%$ larger.

${ }^{1}$ The intent of the implicit vertical velocity damping in the solution for vertically-propagating acoustic modes is to suppress unphysical reflections off of the upper boundary of the domain. By contrast, the regular vertical velocity damping ( $w_{-}$damping $=1$ ), an adjunct to operational model robustness, acts to assure model stability damping vertical velocities which become large locally.

${ }^{2}$ It should be noted that several years of experience of forecasting with the multigrid STD variant has permitted an optimized time step values (72s, 24s). By contrast, a fairly conservative time step value of $18 \mathrm{~s}$ was used for the STD and $3 \mathrm{KM}$ runs to ensure stability. 
Table 1

A cross-comparison of grid properties and associated computing costs for the three variants. All values are normalized by STD values.

\begin{tabular}{lll}
\hline & \# of gridpoints & Compute time \\
\hline STD & 1 & $\mathbf{1}$ \\
3KM & 3.8 & $\mathbf{5 . 0 7}$ \\
MPH & 3.8 & $\mathbf{5 . 8 1}$ \\
\hline
\end{tabular}

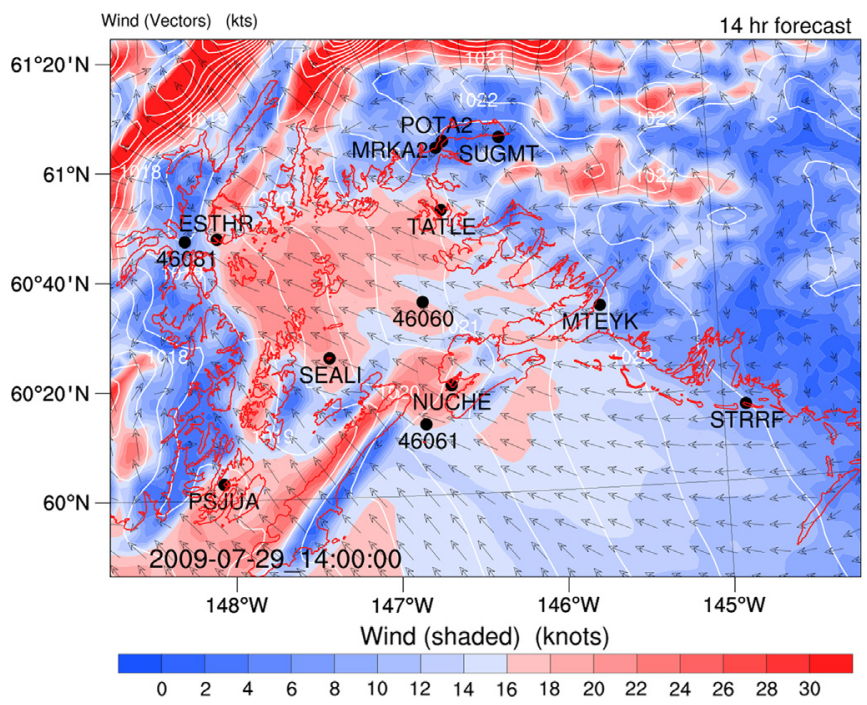

Fig. 7. Locations of the observing sites in PWS used herein, overlaying the $10 \mathrm{~m}$ wind and MSLP forecast for 29 July, 2010. Note that in this case the wind speeds inside PWS, especially in the western Sound, are significantly higher than in the open ocean-NGOA to the south.

\section{Results}

The quantitative discussion of results here is focused primarily on verification of the forecast fields that can be ingested by wave and ocean circulation models: 10 -m wind speed, wind direction, $24 \mathrm{~h}$ precipitation totals. Secondarily we consider mean sea-level pressure (MSLP), and surface temperature.

\subsection{Observing platforms}

Despite the relatively pristine and remote nature of PWS, it has a fairly good automated weather-data mesonet, composed largely of NDBC buoys and C-MAN stations, and Oil Spill Recovery Institute (OSRI) National Resources Conservation Services (NRCS) weather stations, referred to here as "NRCS" stations.

The specific instrumentation and data-logging differed among the various NRCS stations, making these difficult data sets to work with. Several sites' data records had considerable gaps. An additional consideration was that locations desirable for precipitation tend to be wind-sheltered. For these reasons we chose to limit our primary verification of wind to the NDBC platforms and the precipitation verification to the NRCS sites. The locations of the various observations used here are shown in Fig. 7. The latitudes, longitudes, and common names are listed in Table 2.

\subsection{Verification metrics}

It is difficult to objectively measure the performance of highresolution simulations, especially in regions with complex terrain and sparse observations. For evaluation of gridded fields of point observations, several statistical quantities have been suggested
Table 2

A table of common names, latitudes and longitudes for the observing sites denoted in Fig. 7.

\begin{tabular}{llcl}
\hline Common name & Identifier & Longitude & Latitude \\
\hline Esther Island & ESTHR & -147.917 & 60.796 \\
Mt. Eyak & MTEYK & -144.283 & 60.556 \\
Nuchek & NUCHE & -145.350 & 60.333 \\
Port San Juan & PSJUA & -147.950 & 60.050 \\
Seal Island & SEALI & -146.600 & 60.427 \\
Strawberry Reef & STRRF & -143.150 & 60.231 \\
Sugarloaf Mtn & SUGMT & -145.700 & 61.081 \\
Tatitlek & TATLE & -145.317 & 60.867 \\
Western Prince William Sound & 46081 & -147.717 & 60.790 \\
West Orca Bay & 46060 & -145.183 & 60.589 \\
Seal Rocks & 46061 & -145.183 & 60.217 \\
Potato Point & POTA2 & -145.300 & 61.056 \\
Middle Rock Light & MRKA2 & -145.350 & 61.076 \\
\hline
\end{tabular}

(Wilks, 2006) and interpreted physically (e.g., Murphy, 1988). Among these are index of agreement (IOA), wind bearing error (WBE), magnitude of vector error (MVE), Brier skill score (BSS) (Spark and Connor, 2004), mean error (ME) (Hayashi, 2008), bias, root mean square error (RMSE), and mean-squared error skill score (MSESS) (e.g., Ruiz et al., 2010).

In keeping with our practice of ongoing model evaluation at the AEFF, and because they tend to be widely used, we chose to focus on the bias and RMSE, defined as:

bias $=\frac{\sum_{i}^{N}\left(p_{i}-o_{i}\right)}{N}$

$R M S E=\sqrt{\frac{\sum_{i}^{N}\left(p_{i}-o_{i}\right)^{2}}{N}}$

where $N$ is the number of samples (e.g., the number of 36-h surface temperature forecasts in the entire 00 UTC v2.2 data set), and $i$ indicates the $i$ th element in that data-set sequence. Wind direction differences were necessarily constrained:

$-180^{\circ} \leq\left(p_{i}-o_{i}\right) \leq+180^{\circ}$

to avoid the cyclic polar-coordinate discontinuity $\left(0^{\circ} \Leftrightarrow 360^{\circ}\right)$

In most cases, $N=18$, the number of days in the $\mathrm{FE}$, but where the observation data set was incomplete, $N$ necessarily had a smaller value. The analysis was performed for each forecast hour, giving a 49 value $(0 \rightarrow 48 \mathrm{~h})$ time series of $\operatorname{bias}(t)$ and $R M S E(t)$. To provide a figure of merit for each run as a whole, we averaged over all times to produce a single $\overline{R M S E}$ and $\overline{\text { bias }}$ value. To simplify notation in the text, we drop the over bar notation (RMSE $\rightarrow$ RMSE, $\overline{\text { bias }} \rightarrow$ bias).

From the literature, it is difficult to quantify what a "good" value for wind-direction RMSE is, especially when the wind velocity has been analyzed in its vector components $(u, v)$. Also, wind speed statistics are much more commonly reported than wind direction statistics. For gridded numerical models, RMSE values are affected by sample size, grid spacing, length of integration, terrain configuration and seasonality. For example, Bauman (2010) show values of wind-direction RMSE on the Florida Coast averaging about $45^{\circ}$. Sharman et al. (2008), show RMSE values of $69.4^{\circ}$ and $90.6^{\circ}$ for $1-12 \mathrm{~h}$ forecasts and $13-14 \mathrm{~h}$ forecasts, respectively at $850 \mathrm{hPa}$, the closest level to the surface reported on. Wind-direction RMSE values of $59^{\circ}$ and $66^{\circ}$ were found for numerical forecasts made for Sydney 2000 Olympic Games (Spark and Connor, 2004). Comparisons of WRF and MM5 models run over complex terrain in Utah found typical winddirection errors of $50^{\circ}-60^{\circ}$ (Sauter and Henmi, 2004). Wind-speed RMSEs are much more commonly reported and vary widely from 
Table 3

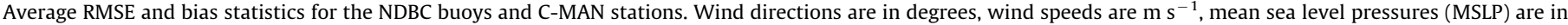
$\mathrm{hPa}$, and temperatures in ${ }^{\circ} \mathrm{C}$.

\begin{tabular}{|c|c|c|c|c|c|c|c|c|c|}
\hline & & \multicolumn{2}{|c|}{ Wind direction } & \multicolumn{2}{|c|}{ Wind speed } & \multicolumn{2}{|l|}{ MSLP } & \multicolumn{2}{|c|}{ Temperature } \\
\hline & & rmse & bias & rmse & bias & rmse & bias & rmse & bias \\
\hline \multirow[t]{3}{*}{46060} & STD & 49.7 & 18.2 & 3.41 & 1.29 & 2.38 & -1.66 & 1.45 & 0.934 \\
\hline & $3 \mathrm{KM}$ & 46.8 & 14.6 & 3.77 & 1.63 & 2.06 & -1.48 & 1.39 & 0.872 \\
\hline & MPH & 45.7 & 12.9 & 3.48 & 1.49 & 2.08 & -1.52 & 1.22 & 0.595 \\
\hline \multirow[t]{3}{*}{46061} & STD & 51.3 & 9.68 & 3.13 & 0.947 & 2.32 & -1.59 & 1.31 & 0.711 \\
\hline & $3 \mathrm{KM}$ & 53.6 & 12.2 & 3.37 & 1.16 & 2.02 & -1.44 & 1.2 & 0.67 \\
\hline & MPH & 53.3 & 8.48 & 3.1 & 0.934 & 2.04 & -1.48 & 1.01 & 0.43 \\
\hline \multirow[t]{3}{*}{46081} & STD & 77.1 & 52.4 & 2.8 & 0.65 & 2.41 & -1.68 & 2.17 & 1.92 \\
\hline & $3 \mathrm{KM}$ & 74.1 & 33.9 & 3.05 & 0.929 & 2.00 & -1.4 & 2.13 & 1.92 \\
\hline & MPH & 67.8 & 20.5 & 2.79 & 0.708 & 2.02 & -1.43 & 1.87 & 1.57 \\
\hline \multirow[t]{3}{*}{ MRKA2 } & STD & 87.7 & -14.3 & 2.92 & -0.05 & 8.72 & -5.47 & 3.56 & 2.51 \\
\hline & $3 \mathrm{KM}$ & 95.9 & -19.2 & 2.94 & 0.47 & 5.33 & -3.53 & 3.15 & 2.67 \\
\hline & MPH & 90.7 & -27.7 & 2.74 & 0.364 & 5.33 & -3.55 & 3.09 & 2.58 \\
\hline \multirow[t]{3}{*}{ POTA2 } & STD & 90.7 & -32.3 & 3.06 & -0.226 & 6.61 & -6.87 & 2.82 & 2.29 \\
\hline & $3 \mathrm{KM}$ & 81.6 & -22.7 & 3.04 & 0.135 & 20.6 & -11.8 & 2.31 & 0.727 \\
\hline & MPH & 80.5 & -21.3 & 2.86 & 0.156 & 20.6 & -11.8 & 2.34 & 0.706 \\
\hline
\end{tabular}

$2.5 \mathrm{~m} \mathrm{~s}^{-1}$ (Spark and Connor, 2004) to $\sim 6 \mathrm{~m} \mathrm{~s}^{-1}$ (e.g., Nutter and Manobianco, 1999; Bauman, 2010).

As with wind direction, wind speed RMSE values are highly dependent on seasonality, geographic location and record length, making intercomparison among different studies problematic. Therefore, our use of RMSE and bias here is mainly as a tool to inter-compare the different variant simulations presented in this study. The values presented above from other studies are presented largely as "reality checks" on our results.

\subsection{STD simulations}

\subsubsection{Buoys 46060 and 46061}

The STD time series for surface wind and direction for NDBC buoy 46060 is given in Fig. 5 (red line) with the black symbols denoting hourly observations. For the most part, the wind direction was fairly accurate. In Table 3 it can be seen that this simulation point had a positive bias of $18.2^{\circ}$ and an RMSE value of $49.7^{\circ}$. Almost directly south of 46060 , Seal Rocks buoy 46061 , at the very entrance to PWS, is considerably more influenced by open-ocean conditions. 46061 showed quite similar RMSE values but with a small bias of $9.68^{\circ}$. This suggests that the larger-scale terrain of PWS is a contributor to systematic error at 46060 . From its central, unsheltered location in PWS, 46061 acts as a bellwether indicating how accurately the simulation is tracking synoptic-scale weather conditions.

Wind speed RMSEs for both 46060 and 46061 were in the neighborhood of $3.0 \rightarrow 3.5 \mathrm{~m} \mathrm{~s}^{-1}$. Mean wind-speed biases calculated in this study for all cases ranged from $0.23 \rightarrow 1.63 \mathrm{~m} \mathrm{~s}^{-1}$ suggesting that the boundary-layer $(\mathrm{BL})$ treatment of wind drag was functioning well. It should be noted however that all the observing buoys are in unobstructed locations, and biases would likely increase where complex terrain was more proximal. RMSE for MSLP are between 2.0 and $2.5 \mathrm{hPa}$ for both buoys. The RMSE time series, $R M S E(t)$, for both buoys show almost no fluctuation from their initial values, suggesting that most of the RMSE comes from the bias $(-1.66$ to $-1.44 \mathrm{hPa})$. Since the bias(t) itself is nearly a flat function in time, the MSLP errors that appear the initial fields continue to appear as an essentially constant offset through and across the simulations.

Temperatures for the buoys showed modest 1.31 and $1.45{ }^{\circ} \mathrm{C}$ RMSE values. These small values may be in part due to the strong role of SSTs in determining atmospheric surface temperatures.
Also, at this latitude and time of year, (day-length $>18 \mathrm{~h}$ ), the impact of the diurnal surface temperature cycle is minimized.

\subsubsection{Buoy 46081}

STD simulations for the western most NDBC buoy, Western Prince William Sound Buoy 46081, showed by far the poorest performance of the sea-level wind-direction observations. Its RMSE value of $77.1^{\circ}$ and very high bias of $52.4^{\circ}$ suggested either instrument performance issues or a fundamental and systematic model error, likely in terrain representation. The location of 46081 is located at the junction of E-W trending Wells Passage and the mouth of NNE-trending Port Wells, with College Fjord at its head. Wells Passage and especially Port Wells are deeplyincised glacial remnants, with terrain rapidly rising from sea level to over $1 \mathrm{~km}$ ASL. This terrain configuration strongly suggests that flow is almost always aligned with one of the two channels (up or down), depending on the prevailing larger-scale pressure gradient.

A time series of winds at 46081 (Fig. 8) demonstrates the strong effect of topography on the surface wind. For the period from around 24 July through 28 July, the observed and STD winds (red line) are nearly $90^{\circ}$ out of phase, with observed winds NNE (down Wells Passage) while the STD winds were essentially from the east. Surface winds for 46060 and 46081 are summarized for the period of the FE in wind rose format in Fig. 9. While the wind direction at 46060 is $\mathrm{E}$ or SE over $60 \%$ of the period, 46081 is N or NE $70 \%$ of the time.

\subsubsection{C-MAN stations MRKA2 and POTA2.}

Coastal-Marine Automated Network (C-MAN) stations Potato Point (POTA2) and Middle Rock Light (MRKA2) are located north of PWS proper in the fjord of Valdez Arm. By design, C-MAN stations are located exactly along the coast line. In areas with steep terrain along the coast, model topography seldom agrees with true sea level at these locations, making C-MAN stations problematic for verification proposes. This is evident in the statistics for POTA2 and MRKA2, with values of $\sim 90^{\circ}$ (RMSE) and $14^{\circ}$ to $32^{\circ}$ (bias). This model/observation elevation mismatch is evident in the MSLP bias, which is more than twice that of the buoy locations. It is also apparent in the higher temperature bias for STD at the C-MAN locations. Note that methods have been suggested to "correct" temperatures to corresponding elevations 


\section{Time Series Wind Speed and Direction}
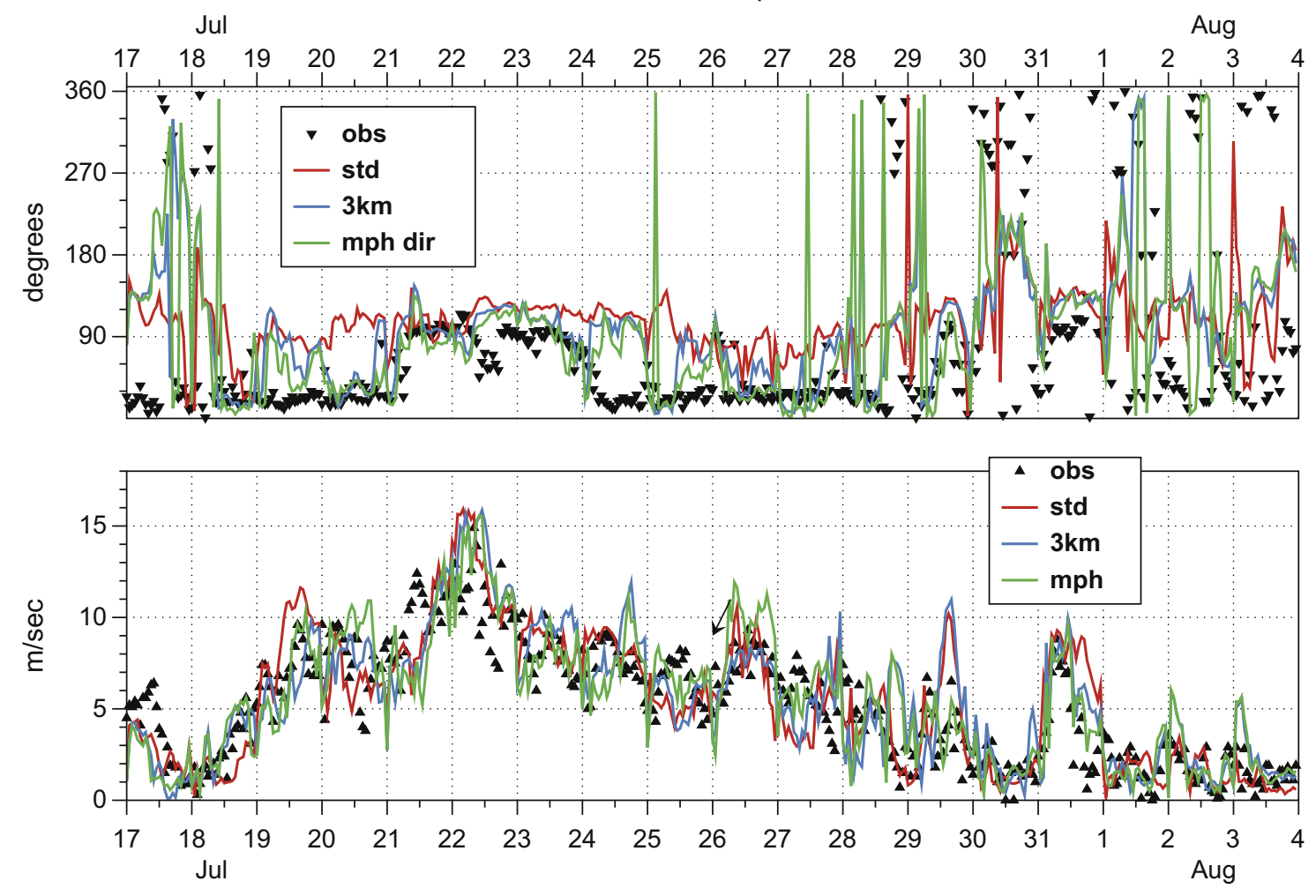

Date

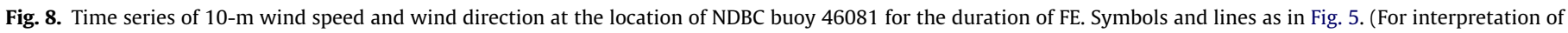
the references to colour in this figure legend, the reader is referred to the web version of this article.)
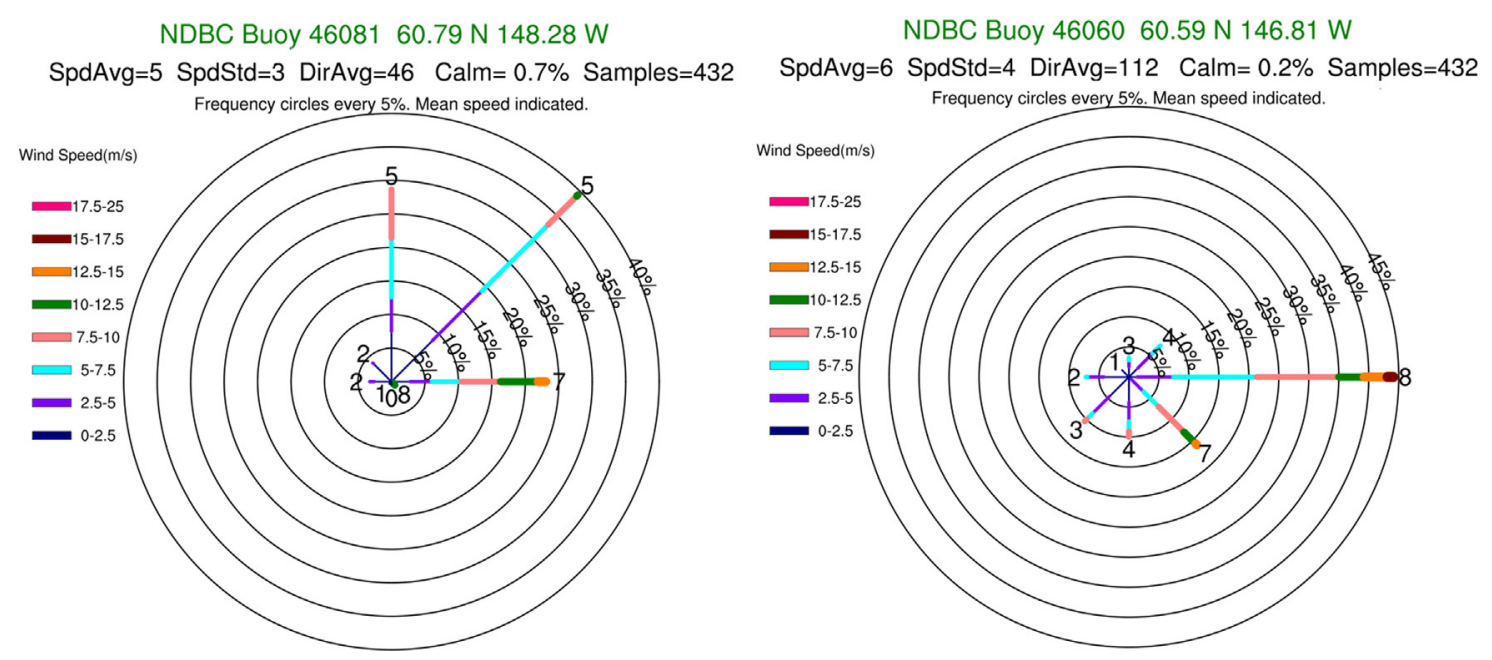

Fig. 9. Wind roses for NDBC buoys 46081 and 46060 for the period of the FE.

(Mass et al., 2002), but these were not implemented for this study as temperature forecasts were of secondary interest.

\subsection{Precipitation}

One of the basic weaknesses of the precipitation verification aspect of this study is a paucity of measurements at higher elevation. Of the NRCS precipitation verification sites used in this study (Fig. 7), only Sugar Loaf Mountain (SUGMT, $232 \mathrm{~m}$ ) and Mt. Eyak (MTEYK, $430 \mathrm{~m}$ ) are sited significantly above MSL in a catchment basin where elevation often exceeds $2500 \mathrm{~m}$. Furthermore, as precipitation amounts typically increase in a superlinear fashion with height (Royer, 1982; Whiteman, 2000), knowledge of precipitation only at lower elevation sites is of little help in developing empirical models of precipitation amount as a function of height (i.e., precipitation $=f^{\mathrm{cn}}(z)$ ). Due to the extremely complex terrain surrounding PWS and associated land surface (typically ice, snow, and or glacier), there may never be robust semi-permanent high-elevation recording stations. The best solution to approximating PWS-basin precipitation at higher 
elevations is probably through quantitative precipitation forecasting (QPF) using models such as PWS-WRF-hence our interest in verification-albeit limited to lower elevations for this study.

There are many approaches to verifying QPF (e.g., Mass et al., 2002; Colle et al., 2000; Ruiz et al., 2010; Hayashi, 2008), all of which have strengths, weaknesses and limitations. In this instance, we are limited by a relatively short duration of record. Our interest also is more climactic than meteorological. It is of course important to forecast the onset, intensity and duration of a precipitation period, but here we are most interested in the QPF total for the FE. Our approach was similar to Colle et al. (2000) in binning precipitation into $24 \mathrm{~h}$ periods, for both the observations and model simulations.

As an example, daily and summary statistics for Port San Juan (PSJUA) appear in Fig. 10. The STD run (red) did quite well in estimating the total accumulated precipitation for the FE, though considerable day-to-day variation between observations and STD is apparent. Comparison with similar plots for the other sites showed that STD did not always perform as well. This comparison also showed that on any given day, there was significant variability in the observed precipitation amounts. While Fig. 10 indicates that precipitation was observed at PSJUA for every day of the FE, this is clearly not the case for every location. Given the dominating orographic influence and the paucity of surface-based convection in PWS, this inter-site variability suggests that subtle

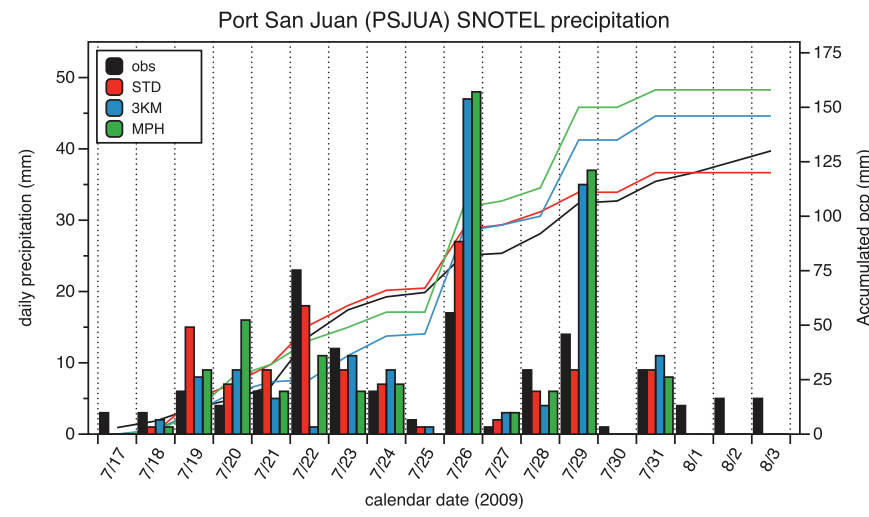

Fig. 10. Daily (bar) and cumulative (line) plots of precipitation ( $\mathrm{mm}$ ) at Port San Juan (PSJUA) for the duration of the FE. (For interpretation of the references to colour in this figure legend, the reader is referred to the web version of this article.)

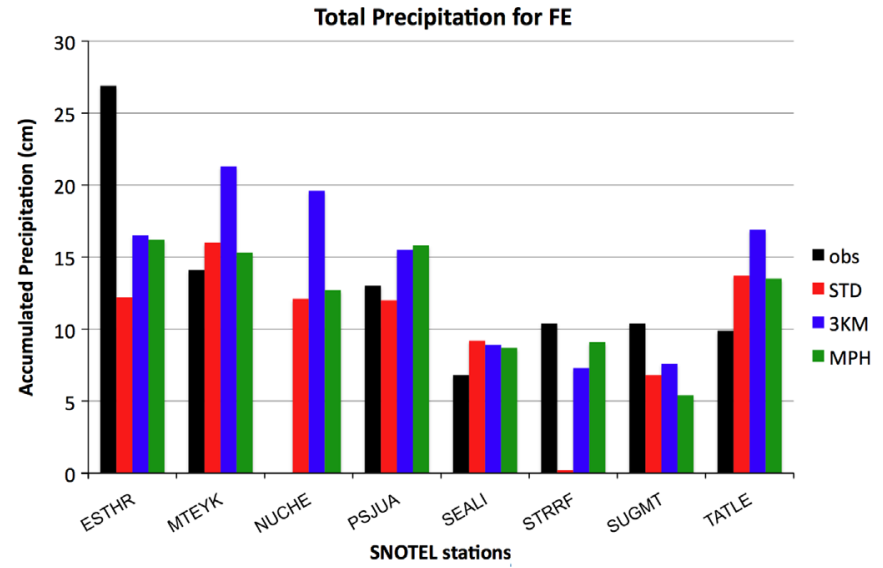

Fig. 11. Total accumulation of precipitation $(\mathrm{cm})$ the for observations and model simulations for the NRCS sites. Note that no observations were available for NUCHE.

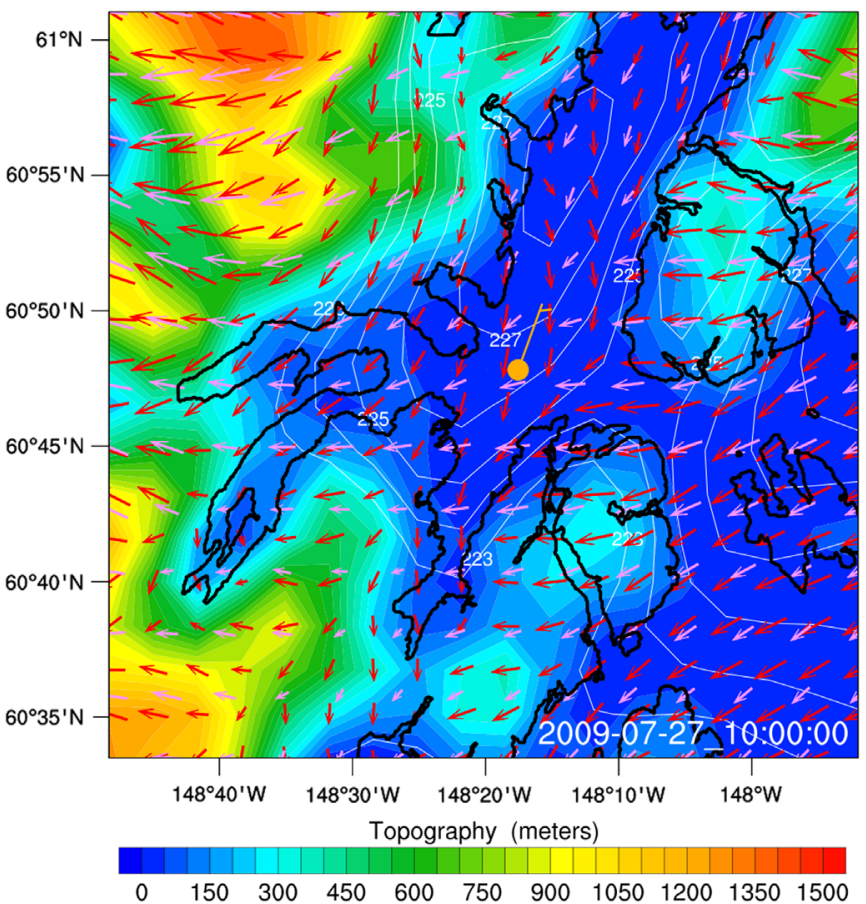

Fig. 12. Topography along the western edge of PWS (shaded). Wind vectors from STD (pink) and MPH (red) and the wind barb for buoy 46081 for 27 July, 10 UTC are shown. The contoured field is MSLP from MPH in dekapascals -20000 $(227 \Rightarrow 2022.7 \mathrm{hPa})$. Note that the MSLP field has an artificial minimum of $2022.3 \mathrm{hPa}$ to eliminate the noisiness inherent in MSLP as calculated in higher terrain. (For interpretation of the references to colour in this figure legend, the reader is referred to the web version of this article.)

differences of low-level flow direction are often critical for the occurrence of precipitation at a given site.

The total accumulated precipitation for observations and simulations for all the NRCS sites is given in Fig. 11. Of the eight sites, Ester Island (ESTHR) clearly dominates the observed precipitation record. This is largely due to a single day, 21 July, when Ester Island site reported almost $11 \mathrm{~cm}$ of precipitation, while STD only produced about $1 \mathrm{~cm}$. Furthermore, none of the other surrounding stations observed anything close to ESTHR's event. In a different environment, this could credibly be ascribed to vigorous local convective activity. For the generally cool and cloudy marine BL typical of warm-season PWS however, it is very difficult to achieve the convective available potential energy (CAPE) needed to produce such intense convection. The maximum temperature of $12.2^{\circ} \mathrm{C}\left(54^{\circ} \mathrm{F}\right)$ and persistent overcast conditions at nearby Cordova, AK (PACV) for 21 July further suggest the potential for convection in PWS was small. Given this, measurement error seems the likeliest explanation. STRRF was along the Grid 2 eastern boundary of STD and was not considered a reliable model point for verification purposes.

\subsection{Results of $3 K M$ and STD variants}

\subsubsection{Winds}

The results in Table 3 for $3 \mathrm{KM}$ and MPH show small improvements over STD in wind statistics at 46060 , with a very slight degradation at 46061 . At western PWS buoy 46081 there was a significant improvement in wind statistics-in particular with respect to wind direction. Some improvement over STD came from the increased grid resolution (3KM), but different physical parameterizations (in this case probably a combination of surface-layer physics and the NOAH Land Surface Model), also showed superior outcomes, especially in terms of wind direction. 
Wind vectors for STD (pink) and MPH (red) in western PWS are shown in Fig. 12, at 10 UTC 27 July, a day with light winds (about $7 \mathrm{kt}$ at 46081). While the winds for the two simulations are similar in most regions, at the location of 46081 (the base of the wind barb) they differ in direction by as much as $90^{\circ}$, with MPH in a very similar direction to the observed wind.

The shaded topography in Fig. 12 demonstrates how deeply incised the terrain is in this end of the Sound and how profoundly it effects the local flow. The MPH MSLP in dekapascals ( -20000$)$ is contoured over the low-lying areas in the figure. A similar figure for the STD MSLP (not shown) reveals an almost flat pressure field in Port Wells (at the buoy location and north). This graphically demonstrates the importance of model configuration for determining local near-surface pressure gradients. In PWS many similar topographic constrictions exist and it is there that an optimal model configuration can show the most improved forecasting skill.

Interestingly, while MPH wind speed RMSE was lowest at C-Man station POTA2, the MPH wind speed bias was the largest of the variants. The bias for the MSLP increased from $-6.9 \mathrm{hPa}$ (STD) to $-11.8 \mathrm{hPa}$ (MPH and STD). Clearly, the topographic representation of the region surrounding POTA2 is significantly higher with the $3 \mathrm{~km}$ grid (hence a more negative pressure bias and less positive temperature bias). We are currently investigating how best to use this observation as a verification tool.

\subsubsection{KM and MPH precipitation}

The results from the accumulated precipitation for the $3 \mathrm{KM}$ and MPH variants varied widely from site to site (Fig. 11). Overall, QPF for both variants was more than that observed. In most cases, 3KM produced the most precipitation. While overall, MPH was probably the best predictor of the three runs, no variant dominated the precipitation prediction.

At ESTHR, the site with by far the most observed precipitation, 3KM and MPH both produced more precipitation, but still far short of what was observed. Investigation of the time series of the individual stations, showed a great deal of day-to-day variability. At PSJUA, for example (Fig. 10), there were two days (July 26 and July 29) when $3 \mathrm{KM}$ and MPH grossly over-forecast the $24 \mathrm{~h}$ precipitation totals ${ }^{3}$ while STD had better results. Such over-forecasting was evident in other stations' records (not shown) as well, thought not on particular days. From the small sample size considered here it is difficult to draw any significant conclusions as to which model variant was the most consistent for daily QPF purposes.

\section{Summary and conclusions}

In this paper we reviewed the results of an 18-day highresolution atmospheric forecasting field experiment where special attention was given to surface meteorological properties and precipitation. Upon reviewing the results, it was determined that certain modifications might be incorporated in the PWS-WRF modeling system to improve the forecast results. These can be considered to be of two distinct varieties: model geometry and physical parameterizations. Two further simulations of the same 18-day period were conducted: (1) with the enhanced model geometry, and (2) with both the enhanced geometry and the updated model physics.

As expected, with all variants the error values generally showed improvement over the first few hours as the coarser scale initial

\footnotetext{
${ }^{3}$ With our method of accumulating 24 -h precipitation totals it is possible that the mistiming of a precipitation event could lead to binning errors for the day in question. This should be evident however in the totals for the preceding and following days. That was not the case here.
}

fields adjusted to the more highly-resolved topography, with the greatest change in RMSE occurring during the first two hours. The expected gradual degradation of RMSE values over the course of the $48 \mathrm{~h}$ simulations was harder to detect at some stations. All such trends would likely be more detectable with a sample size $\gg 18$.

Other investigators have actually found degraded objective verification measurements with increased horizontal model resolution. This may result from errors in timing. While increased resolution more sharply defines boundaries (e.g. fronts, outflow boundaries), at the same time it makes even slight timing errors more pronounced than would be seen in a coarser resolution model with essentially the same timing errors. In our case, we found modest improvements in going from a $4-\mathrm{km} \Delta x, y$ grid to 3-km $\Delta x, y$. This modification was performed concomitantly with an increased vertical resolution ( $54 \mathrm{~m}$ vs. $32 \mathrm{~m}$ for a first level) however, making it hard to ascribe improvements to vertical or horizontal resolution. Incremental improvement was also gained in changing model physics.

Fundamental conclusions from the research reported on here include:

- The weather during the summer-time FE was typical of the NGOA/PWS in that it was characterized by a number of minor disturbances rotating around an anchored low, but with no major storms in the Gulf.

- The basic PWS-WRF modeling system as implemented operationally for the FE performed well, especially considering the extremely complex terrain comprising the greater PWS region.

- Modifications to the initial PWS-WRF modeling system showed improvement in predicting surface variables, especially where the ambient flow interacted strongly with the terrain, or where terrain-induced flows interacted with the larger-scale flows.

- Prediction of precipitation on an accumulated basis was more accurate than QPF on a day-to-day basis.

- The period of the FE (18 days) was on the short side in terms of statistical assessment of the model variant performance.

- The 18-day period was not sufficient in order to determine the ability of QPF by PWS-WRF.

The PWS-WRF variants need to be rigorously tested in a much wider variety of weather conditions than those occurring during the relatively benign FE. The NGOA is well known for its fierce weather, especially during the cold season, and all PWS-WRF variants need to be tested in these conditions. In cooperation with the NWS Anchorage Forecast Office, the AEFF is currently running all variants operationally twice daily on a year-round basis, with objective assessment of forecasts being extended beyond the PWS into the Cook Inlet region of the NGOA.

\section{Acknowledgments}

The authors would like to extend their thanks to all of the assistance given by fellow members of the Sound Predictions Field Experiment. We would also like to thank the Oil Spill Recovery Institute (OSRI) and the Alaska Ocean Observing System (AOOS) for their past and ongoing support. Recognition also goes to the University of Alaska Anchorage; in particular to the Community and Technical College (CTC) for support of the Alaska Experimental Forecast Facility (AEFF), and the Environment and Natural Resources Institute (ENRI) for their support of the Alaska State Climate Center (ASCC). 


\section{References}

Bauman III, W.H., 2010. An objective verification of the North American Mesoscale Model for Kennedy Space Center and Cape Canaveral Air Force Station. 14th Conference on Aviation, Range, and Aerospace Meteorology. American Meteorological Society, Atlanta, GAAmerican Meteorological Society, Atlanta, GA 5pp.

Brooks, H.E., Doswell, C.A., 1993. New technology and numerical weather prediction-a wasted opportunity? Weather 48, 173-177.

Colas, F., Wang, X., McWilliams, J.C., Chao, Y. The seasonal cycle of freshwater content in Prince William Sound, Alaska, in preparartion.

Colle, B.A., Mass., C.F., 2000a. The 5-9 February 1996 flooding event over the Pacific Northwest: sensitivity studies and evaluation of the MM5 precipitation forecasts. Monthly Weather Review 128, 593-617.

Colle, B.A., Mass, C.F., 2000b. High-resolution observations and numerical simulations of easterly gap flow through the Strait of Juan de Fuca on 9-10 December 1995. Monthly Weather Review 128, 2398-2422.

Colle, B.A., Mass, C.F., Westrick, K.J., 2000. MM5 precipitation verification over the Pacific Northwest during the 1997-99 cool seasons. Weather and Forecasting 15, 730-744.

Davis, C., Warner, T., Astling, E., Bowers, J., 1999. Development and application of an operational, relocatable, mesogamma-scale weather analysis and forecasting system. Tellus $51 \mathrm{~A}, 710-727$.

Doyle, J.D., 1997. The influence of mesoscale orography on a coastal jet and rainband. Monthly Weather Review 125, 1465-1488.

Hayashi, S., Aranami, K., Saito, K., 2008. Statistical verification of short term NWP and WRF-ARW with $20 \mathrm{~km}$ horizontal resolution around Japan and Southeast Asia. Scientific Online Letters on the Atmosphere 4, 133-136.

Hong, S.-Y., Lim, J.-O.J., 2006. The WRF single-moment 6-class microphysics scheme (WSM6). Journal of the Korean Meteorological Society 42, 129-151.

Hong, S.-Y., Dudhia, J., Chen, S.-H., J., 2004. A revised approach to ice microphysical processes for the bulk parameterization of clouds and precipitation. Monthly Weather Review 132, 103-120.

Hong, S.-Y., Noh, Y., Dudhia, J., 2006. A new vertical diffusion package with an explicit treatment of entrainment processes. Monthly Weather Review 134, 2318-2341.

Janjic, Z.I., 1996. The surface layer in the NCEP Eta model. Eleventh Conference on Numerical Weather Prediction, American Meteorological Society, Norfolk, VA 19-23 August, pp. 354-355.

Janjic, Z.I., 2002. Nonsingular implementation of the Mellor-Yamada level 2.5 scheme in the NCEP Meso model. NCEP Office Note 437, 61.

Jankov, L.W., Gallus, W.A., Segal, M., Shaw, B., Koch, S.E., 2005. The impact of different WRF model physical parameterizations and their interactions on warm season MCS rainfall. Weather and Forecasting 20, 1048-1060.

Knievel, J.C., Bryan, G.H., Hacker, J.P., 2007. Explicit numerical diffusion in the WRF model. Monthly Weather Review 135, 3808-3824.

Klemp, J.B., Skamarock, W.C., Dudhia, J., 2007. Conservative split-explicit time integration methods for the compressible nonhydrostatic equations. Monthly Weather Review 135, 2897-2913.

Mass, C.F., Ovens, D., Westrick, K., Colle, B.A., 2002. Does increasing horizontal resolution produce more skillful forecasts? Bulletin of the American Meteorological Society 83, 407-430.

McQueen, J.T., Draxler, R.R., Rolph, G.D., 1995. Influence of grid size and terrain resolution on wind field predictions from an operational mesoscale model. Journal of Applied Meteorology 34, 2166-2181
Mesquita, M.D.S., Atkinson, D.E., Hodges, K.I., 2010. Characteristics and variability of storm tracks in the North Pacific, Bering Sea, and Alaska. Journal of Climate 23, 294-311.

Murphy, A.H., 1988. Skill scores based on mean square error and their relationships to the correlation coefficient. Monthly Weather Review 116, 2417-2424.

Nutter, P.A., Manobianco, J., 1999. Evaluation of the 29-km Eta model. Part I: objective verification at three selected stations. Weather and Forecasting 14 5-17.

Olsson, P.Q., Harington, J.Y., Feingold, G., Cotton, W.R., Kreidenweis, S., 1998. Exploratory cloud-resolving simulations of Boundary layer Arctic stratus clouds. Part I: Warm-season clouds. Atmospheric Research 47-48, 573-597.

Olsson, P.Q., Harrington, J.Y., 2000. Dynamics and energetics of the cloudy boundary layer in simulations of off-ice flow in the marginal ice zone. Journal of Geophysical Research 105, 11889-11899.

Royer, T.C., 1982. Coastal fresh water discharge in the northeast Pacific. Journal of Geophysical Research 87, 2017-2021.

Ruiz, J.J., Saulo, C., Nogues-Paegle, J., 2010. WRF model sensitivity to choice of parameterization over South America: validation against surface variables. Monthly Weather Review 138, 3342-3355.

Sauter, B., Henmi, T., 2004. Average forecast errors using MM5 and WRF over complex terrain: Utah, July/August 2003 and January/February 2004. Army Research Laboratory, White Sands Missile Range, NM 16 pp.

Schoch, G.C. McCammon, M. Demonstrating an observing system in Prince William Sound, Alaska. Continental Shelf Research, doi:10.1016/j.csr.2011.12. 011, in press.

Sharman, R.D., Liu, Y., Sheu, R.-S., Warner, T.T., Rife, D.L., Bowers, J.F., Clough, C.A Ellison, E.E., 2008. The operational mesogamma-scale analysis and forecast systems of the U.S. Army Test and Evaluation Command. Part III: Forecasting with secondary-application models. Journal of Applied Meteorology and Climatology 47, 1105-1122.

Skamarock, W.C., Klemp, J.B., 1992. The stability of time-split numerical methods for the hydrostatic and the nonhydrostatic elastic equations. Monthly Weather Review 120, 2109-2127.

Skamarock W.C., Klemp, J.B., Dudhia, J., Gill, D.O., Barker, D.M., Duda, M.G., Huang X.-Y., Wang, W., Powers. J.G., 2008. A description of the advanced research WRF Version 3. NCAR Technical Note, National Center for Atmospheric Research, Boulder, CO.

Spark, E., Conner, G.J., 2004. Wind Forecasting for the sailing events at the Sydney 2000 Olympic and Paralympic Games. Weather and Forecasting 19, 181-199.

Stabeno, P.J., Bond, N.A., Hermann, A.J., Kachel, N.B., Mordy, C.W., Overland, J.E. 2004. Meteorology and oceanography of the northern Gulf of Alaska. Continental Shelf Research 24, 859-897.

Wicker, L.J., Skamarock, W.C., 2002. Time splitting methods for elastic models using forward time schemes. Monthly Weather Review 130, 2088-2097.

Whiteman, C.D., 2000. Mountain meteorology: fundamentals and applications Oxford University Press $355 \mathrm{pp}$

Wilks, D.S., 2006. Statistical Methods in Atmospheric Sciences, second ed Academic Press, 627 pp.

Wilson, J.G., Overland, J.E., 1986. Meteorology of the northern Gulf of Alaska. In: Hood, D.W., Zimmerman, S.T., (Eds.) The Gulf of Alaska: Physical Environment and Biological Resources, DOC/NOAA, DOI, pp. 31-54. 